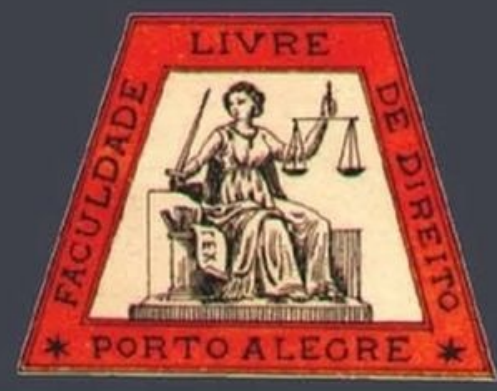

\title{
Questões controversas sobre a aplicação da "Lei Maria da Penha" no âmbito do Direito Penal
}

Controversial issues about the application of "Maria da Penha" law in the criminal sphere

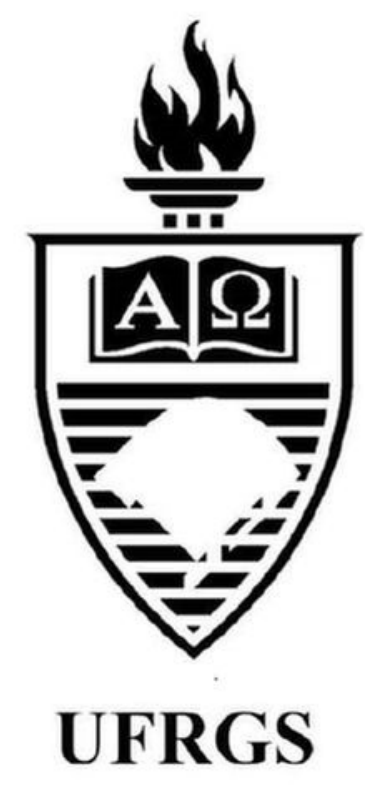

Frederico Gomes de Almeida Horta

Universidade Federal de Minas Gerais

Marina Ferreira de Melo Burrel

Universidade Federal de Minas Gerais

Matheus Pessoa de Faria

Universidade Federal de Minas Gerais 


\title{
Questões controversas sobre a aplicação da "Lei Maria da Penha" no âmbito do Direito Penal ${ }^{1}$
}

\author{
Controversial issues about the application of "Maria da Penha" law in the criminal sphere
}

\author{
Frederico Gomes de Almeida Horta*
}

Marina Ferreira de Melo Burrel ${ }^{* *}$

Matheus Pessoa de Faria ${ }^{* * *}$

\section{REFERÊNCIA}

BURREL, Marina Ferreira de Melo; FARIA, Matheus Pessoa de; HORTA, Frederico Gomes de Almeida. Questões controversas sobre a aplicação da "Lei Maria da Penha" no âmbito do Direito Penal. Revista da Faculdade de Direito da UFRGS, Porto Alegre, n. 39, vol. esp., p. 92-111, dez. 2018.

\begin{abstract}
RESUMO
$\mathrm{O}$ trabalho aponta e analisa questões controversas da Lei $\mathrm{n}^{\circ}$ 11.340/2006, a partir do contexto no qual se consolidou. Por meio de pesquisas bibliográficas, análises doutrinárias e jurisprudenciais, pretende-se abordar os problemas percebidos na aplicação deste diploma no âmbito penal. Analisa-se, inclusive, um caso prático vivenciado na Divisão de Assistência Judiciária da Universidade Federal de Minas Gerais, demonstrando-se consequências da utilização de dispositivos da "Lei Maria da Penha" de maneira incoerente com a sistemática do processo penal constitucional do Estado Democrático de Direito. Esclarece o procedimento previsto na Lei e suas implicações penais e, a partir disso, questiona a imposição de restrições de liberdade ao suposto agressor no procedimento de medidas protetivas. Destaca, ainda, os problemas relacionados à prisão preventiva na Lei Maria da Penha, especialmente no que toca ao tempo de sua duração e à sua aplicabilidade em infrações puníveis com penas detenção ou mera prisão simples. Por fim, aborda a problemática da prisão preventiva com a finalidade de garantir o cumprimento de medidas protetivas.
\end{abstract}

\section{ABSTRACT}

The paper points out and analyzes controversial issues of Act 11,340/2006, from the context of its consolidation. Through bibliographical research, doctrinal analysis and case law, it intendeds to address the problems perceived in the application of this Act in the criminal field. It also analyzes a lawsuit sponsored by the "Divisão de Assistência Judiciária" of the "Universidade Federal de Minas Gerais", demonstrating the consequences of the use of provisions of the "Maria da Penha Act" in a manner incoherent with the systematic of constitutional criminal proceedings created by the Rule of Law. It clarifies the procedure provided for in the Act and its criminal implications and, with this, questions the imposition of restrictions of freedom on the supposed aggressor in the procedure of protective measures. It also highlights the problems related to pre-trial detention in the Maria da Penha Law, especially with regard to the duration of the sentence and its applicability to offenses punishable by imprisonment or mere simple arrest. Finally, it addresses the problem of pre-trial detention in order to guarantee compliance with protective measures.

\footnotetext{
${ }^{1}$ Este artigo é fruto das pesquisas realizadas pelo Professor Frederico Gomes de Almeida Horta na linha de pesquisa Poder, cidadania e desenvolvimento no Estado Democrático de Direito, projeto coletivo Liberdade, segurança jurídica e limites ao poder penal no Estado Democrático de Direito, do Programa de Pós Graduação em Direito da UFMG, tendo sido desenvolvido juntamente com os estudantes de graduação e estagiários Marina Ferreira de Melo Burrel e Matheus Pessoa, da Divisão de Assistência Judiciária (DAJ) da Faculdade de Direito da UFMG, a partir casos reais vivenciados neste programa de extensão universitária.

${ }^{*}$ Professor Adjunto de Direito e Processo Penal da Universidade Federal de Minas Gerais (UFMG). Doutor em Direito pela UFMG (2013). Mestre em Ciências Penais pela UFMG (2006). Especialista em Direito Penal Econômico e Europeu pela Universidade de Coimbra (Portugal, 2007). Bacharel em Direito pela UFMG (2004).

** Graduanda em Direito pela Universidade Federal de Minas Gerais (UFMG).

** Graduando em Direito pela UFMG. Pesquisador PIBIC-CNPq.
} 
PALAVRAS-CHAVE

Lei Maria da Penha. Direito Penal. Prisão Preventiva.

Crime de desobediência. Contravenções Penais. Detenção.

\section{KEYWORDS}

"Maria da Penha" Act. Criminal Law. Pre-trial detention. Contempt of court. Misdemeanor. Detention.

\section{SUMÁRIO}

Introdução. 1. Contexto histórico da Lei no 11.340 de 2006. 2. As espécies de medidas protetivas de urgência prevista na "Lei Maria da Penha". 3. O contraditório e a ampla defesa na "Lei Maria da Penha". 4. A Prisão Preventiva como medida protetiva ou sanção processual. 4.1. Duração da Prisão Preventiva. 4.2. Da (in)aplicabilidade da prisão preventiva em caso de contravenção penal e crime punível com pena de detenção: doutrina, jurisprudência e caso da Divisão de Assistência Judiciária da UFMG. 5. Crime de desobediência por descumprimento das medidas protetivas de urgência. Conclusão. Referências.

\section{INTRODUÇÃO}

No Brasil, o processo de enfrentamento à violência doméstica contra a mulher remonta à década de $1970 .^{2}$ Mas seu marco legal mais significativo só veio à lume com a Lei no 11.340 , de 7 de agosto de 2006, também conhecida como Lei "Maria da Penha". Esta lei representa importante mecanismo para a proteção e efetivação dos direitos fundamentais das mulheres vítimas de violência no país. Não obstante, traz em seu bojo inovações polêmicas, algumas delas carentes de plena regulamentação, que tem gerado divergências doutrinárias e jurisprudenciais de grande repercussão.

Por exemplo, a "Lei Maria da Penha" prevê uma série de medidas protetivas para coibir a violência doméstica contra a mulher e autoriza sua imposição "de imediato" (art. 19, §1 ${ }^{\circ}$, da Lei 11.340/06), gerando polêmica sobre a constitucionalidade da aplicação restrição de direitos e liberdades que elas implicam, sem prévia manifestação do suposto agressor. Além disso, reconhece como medida protetiva até mesmo a decretação de prisão preventiva do suspeito, sem estabelecer duração máxima dessa prisão. Tem-se aí uma relevante lacuna, já que tal medida não pode se perpetuar, de forma desproporcional e injustificada.
O diploma em análise também não esclarece se o descumprimento de medidas protetiva de urgência acarreta a automática decretação da prisão preventiva, se tal configura crime de desobediência ou se dá ensejo à tomada de providência alternativa. E enseja dúvida acerca da possibilidade de decretação da prisão preventiva como medida cautelar em face de indivíduos suspeitos do cometimento de infrações apenadas com pena privativa de liberdade não superior a 4 anos, mera detenção ou mesmo prisão simples.

Nesse sentido, o trabalho aponta e analisa pontos específicos da "Lei Maria da Penha" que necessitam de especial atenção dos intérpretes e aplicadores do direito, a fim de contribuir para o debate acadêmico sobre o tema.

\section{CONTEXTO HISTÓRICO DA LEI No 11.340 DE 2006}

A Comissão Interamericana de Direitos Humanos recebeu, no dia 20 de agosto de 1998, uma denúncia com base no artigo 12 da Convenção Interamericana para Prevenir, Punir e Erradicar a Violência contra a Mulher, bem como nos artigos 44 e 46 da Convenção Americana sobre Direitos Humanos.

\footnotetext{
2 TAVARES, Márcia Santana; SARDENBERG, Cecília M. B.; GOMES, Márcia Queiroz de C. Feminismo, Estado e Políticas de Enfrentamento à Violência contra mulheres: monitorando a Lei Maria da Penha. Labrys Estudos Feministas, Florianópolis: UFSC, jun./dez, 2011.
} 
De acordo com os relatos dos peticionários, uma brasileira teria sofrido tentativas de homicídio por parte de seu marido, que pretendeu eletrocutá-la durante o banho e, posteriormente, efetuou disparos com arma de fogo contra ela. $\mathrm{Na}$ denúncia, foi afirmado que o cônjuge agredia sua esposa e filhas durante todo o tempo de matrimônio. No entanto, e não obstante o esforço empregado pela vítima em acionar a jurisdição brasileira, o Estado não ofereceu solução efetiva e em prazo razoável para o problema, não tendo havido uma decisão transitada em julgado que condenasse o autor das agressões, mesmo após mais de quinze anos da judicialização do caso.

A Comissão concluiu que houve, de fato, omissão por parte do Estado brasileiro no caso em comento. Além disso, ponderou que as agressões domésticas contra mulheres são, no Brasil, desproporcionalmente maiores em relação às que ocorrem contra homens. Afirmou-se, ainda, que há no país um contexto de agressões e abusos rotineiros contra mulheres.

Ao condenar o Estado brasileiro, a Comissão recomendou a tomada de providências, inclusive por meio da adoção de políticas públicas, a fim de combater a violência contra a mulher. Dentre essas, destaca-se a de que o Brasil prosseguisse e intensificasse "o processo de reforma que evite a tolerância estatal $e \quad o$ tratamento discriminatório com respeito à violência doméstica contra mulheres no Brasil". ${ }^{3}$

Dessa reforma, imposta ao país, surgiu a Lei $\mathrm{n}^{\circ} 11.340$, de 7 de agosto de 2006, que também ficou conhecida, em homenagem à vítima da denúncia supramencionada, como "Lei Maria da Penha". Essa lei, em apertadíssima síntese, visa coibir e prevenir a violência familiar e doméstica contra a mulher, proteger e vítima e

\footnotetext{
3 COMISSÃO INTERAMERICANA DE DIREITOS HUMANOS. Caso 12.051. Relatório n $n^{o}$ 54/01. Disponível em:

<http://www.sbdp.org.br/arquivos/material/299_Relat\%20 n.pdf $>$. Acesso em: 25 jun. 2017.
}

responsabilizar de maneira específica

os agressores.

A Lei Maria da Penha se apresenta em um contexto histórico sociocultural de "submissão" da mulher em relação ao homem, dependência econômica, patriarcalismo e outros problemas sociais e culturais. Representa, portanto, instrumento político-criminal de repressão à violência fundada no gênero feminino, no âmbito das relações afetivas ou familiares. Coíbe não apenas a violência física, mas também a psicológica, patrimonial, moral e sexual. São consideradas manifestações dessas violências, por exemplo, a restrição da comunicação ou liberdade de locomoção, a privação financeira e a calúnia, difamação ou injúria contra a vítima, conforme o artigo $7^{\circ}$ da Lei n. ${ }^{\circ} 11.343 / 06$.

Não obstante sua reconhecida importância para o controle da violência contra a mulher, esta lei demanda elaboração doutrinária e jurisprudencial que resolva pontos controversos, aparando eventuais conflitos ou incompatibilidades com um sistema de persecução penal próprio de um Estado Democrático de Direito, que observe as garantias constitucionais do acusado. Tais questões constituem o objeto de análise do presente trabalho.

\section{AS ESPÉCIES DE MEDIDAS PROTETIVAS DE URGÊNCIA PREVISTA NA "LEI MARIA DA PENHA"}

Por certo, incumbe ao juiz, polícia e Ministério Público o dever de tomar as medidas cabíveis necessárias para zelar pela segurança da vítima da violência, de forma célere e eficaz. ${ }^{4} \mathrm{Um}$ importante instrumento para prevenir e coibir violência familiar e doméstica contra a mulher é a

${ }^{4}$ DIAS, Maria Berenice. A Lei Maria da Penha na Justiça: a efetividade da Lei 11.340/2006 de combate à violência doméstica e familiar contra a mulher. São Paulo: Revista dos Tribunais, 2007. 
aplicação, pelas autoridades competentes, das medidas protetivas elencadas na "Lei Maria da Penha".

Ao abordarem o tema, Rosane M. Reis Lavigne e Cecilia Perlingeiro destacam que se trata "de mecanismo legal destinado a gerar procedimentos judiciais, políticas e serviços especializados, particularmente no âmbito do sistema de justiça, operando em rede, com perspectiva interdisciplinar e foco na mulher usuária do sistema". 5

Dentre tais medidas, destacam-se as elencadas no artigo 22 da lei em análise: a suspensão da posse ou restrição do porte de armas, o afastamento do lar, domicílio ou local de convivência com a ofendida, a proibição de determinadas condutas como, por exemplo: a aproximação ou o contato por qualquer meio de comunicação com ofendida (vítima), seus familiares e testemunhas, a fixação do limite mínimo de distância entre estes e o agressor e, ainda, a proibição de frequência a determinados lugares, a fim de preservar a integridade física e psicológica da ofendida. É possível, ainda, a restrição ou suspensão de visitas aos dependentes menores, ou o estabelecimento de prestação de alimentos provisionais ou provisórios. Cabe salientar que a aplicação dessas medidas protetivas de urgência não impede a utilização de outras medidas previstas em lei, conforme o $§ 1^{\circ}$ do artigo 22 da Lei n. ${ }^{\circ}$ 11.343/06.

A Lei Maria da Penha prevê, em seus artigos 23 e 24, medidas protetivas de urgência direcionadas à vítima da suposta agressão, como, por exemplo, o encaminhamento da ofendida e seus dependentes a programa de proteção ou atendimento, o afastamento da ofendida do lar, sem prejuízo dos direitos relativos a bens, guarda dos filhos e alimentos e a separação de corpos por

\footnotetext{
${ }^{5}$ LAVIGNE, Rosane M. Reis; PERLINGEIRO, Cecília. Das medidas protetivas de urgência: $\operatorname{artigos} 18$ a 21. In: CAMPOS, Carmen Hein de. Lei Maria da Penha comentada em uma perspectiva jurídico-feminista. Rio de Janeiro: Lumen Juris, 2011. p. 291.
}

determinação judicial (separação entre vítima e agressor). Algumas providências têm a finalidade de garantir a proteção dos bens da sociedade conjugal ou do patrimônio particular da mulher. Assim, por exemplo, a prestação de caução provisória, mediante depósito judicial, por perdas e danos decorrentes da prática da violência. E por fim, há a possibilidade, mencionada na introdução, de prisão preventiva do agressor, desde que configuradas as hipóteses para seu cabimento.

Muito se discute sobre quais as medidas adequadas para coibir a violência doméstica em cada caso concreto. De fato, o tema é complexo, uma vez que a escolha eficaz do instrumento a ser utilizado para resolver cada conflito deve observar suas peculiaridades. E há quem sustente que a prevenção desse tipo de violência deve se consolidar principalmente através de políticas públicas de conscientização. Segundo Marília Montenegro: "Não há dúvidas de que a melhor forma de combater a violência doméstica é através de políticas públicas não repressivas, conscientizando a população, principalmente pela educação para as novas gerações, como estabelecem os incisos III, V, VII VIII e IX do art. $8^{\circ}$ da Lei n ${ }^{\circ} 11.340 / 2006 " .6$

\section{O CONTRADITÓRIO E A AMPLA DEFESA NA "LEI MARIA DA PENHA"}

Uma importante peculiaridade da Lei $\mathrm{n}^{\circ}$ 11.340/2006 é o fato de que, não obstante a regra estabelecida pela Lei ${ }^{\circ} 12.403 / 2011$, segundo a qual a concessão de medidas de urgência em geral exige a prévia a manifestação do acusado, a Lei Maria da Penha admite a dispensa do prévio contraditório quando da concessão de suas medidas protetivas específicas. ${ }^{7}$

\footnotetext{
${ }^{6}$ MONTENEGRO, Marília. Lei Maria da Penha: uma análise criminológico-crítica. p. 117

${ }^{7}$ CASTRO, Fabiana Oliveira Bastos. O Contraditório prétivo na decretação das medidas cautelares previstas na Lei Maria da Penha: uma perspectiva evolutiva. In: XXIV
} 
Assim, na sistemática da Lei $n^{\circ}$ 11.340/2006, após o registro da ocorrência de suposta violência doméstica e familiar contra a mulher, a autoridade policial deve remeter ao juiz competente, no prazo de 48 (quarenta e oito) horas, um expediente apartado com o pedido para a concessão de medidas protetivas de urgência, nos termos do seu artigo 12, inciso III. Desse modo, as medidas protetivas de urgência podem ser concedidas liminarmente, lastreadas em uma possível ameaça à integridade física e psíquica da vítima. Segundo Juliana Garcia Belloque:

As medidas protetivas de urgência são claramente medidas cautelares, adotadas em cognição sumária na fase inquisitiva ou judicial, inclusive sem oitiva da parte afetada, não definitivas e que visam assegurar o resultado do processo de apuração dos fatos supostamente criminosos, culminando na eventual punição do agressor. ${ }^{8}$

Isso ocorre porque, para a lei, parece bastar o boletim de ocorrência policial e as declarações da vítima para se deferir as medidas. Pois raramente se coletam outros elementos de informações nessas circunstâncias. Na maioria das vezes, a concessão de medidas protetivas se baseia apenas na palavra da mulher, atendendo a lógica de certo modo alarmista que o legislador impõe, baseado na premissa da vulnerabilidade da mulher em situação de violência doméstica.

Portanto, é possível que sejam concedidas, inaudita altera pars, medidas como o afastamento do agressor da ofendida e de seus familiares mediante fixação de uma distância mínima, ou a proibição de comunicação com a ofendida e de frequentar determinados lugares. Trata-se de uma exceção à regra geral, segundo a qual o Magistrado deve, primeiramente, ouvir as partes, para, somente após fazê-lo, proferir sua decisão. Uma exceção que soluciona um dilema em favor

CONGRESSO NACIONAL DO CONPEDI, 19., 2015, Florianópolis. Anais Processo, Jurisdição e efetividade da Justiça I. Florianópolis: CONPEDI, 2015.

${ }^{8}$ BELLOQUE, Juliana Garcia. Das medidas protetivas que obrigam o agressor - artigos 22. In: CAMPOS, Carmen da ofendida. Pois se por um lado cumpre ao Estado garantir a máxima proteção da integridade e dignidade da mulher, por outro, faz-se necessária a observância dos princípios constitucionais da ampla defesa e do contraditório.

O deferimento das medidas de urgência implica em restrições à liberdade do suposto agressor. E, se a Lei Maria da Penha não exige o prévio contraditório, tem-se a possibilidade de que o suspeito sofra restrições como, por exemplo, ficar impedido de frequentar determinados locais ou de se aproximar da vítima, para, somente após a intimação, geralmente apenas pela via recursal ou após o efetivo ajuizamento de ação penal contra, vir a exercer o contraditório e ampla defesa. Há casos em que o acusado necessita frequentar locais próximos à vítima, como por exemplo, nas situações em que ambos trabalham ou estudam em um mesmo edifício. Nestas hipóteses, a interdição prejudica consideravelmente as atividades habituais $\mathrm{e}$ ocupações do suposto agressor, com impactos os mais severos sobre sua vida.

$\mathrm{O}$ artigo 282, $\$ 3^{\circ}$, do Código de Processo Penal prevê que as medidas cautelares pessoais podem ser concedidas sem oitiva da parte afetada, condicionando, todavia, a validade deste procedimento aos casos nos quais houver efetivo perigo de ineficácia da medida ou urgência. Temse sustentado a aplicabilidade deste dispositivo, reformado pela Lei no 12.403/2011, à "Lei Maria da Penha". Assim, por exemplo, Fabiana Oliveira Bastos Castro. Para esta autora, mesmo para a concessão das medidas protetivas específicas da Lei $\mathrm{n}^{\circ} 11.340 / 2006$ é necessário o prévio exercício do contraditório pelo acusado. ${ }^{9}$ Por outro lado, há quem defenda que a concessão das medidas sem oitiva do acusado, "diante da

Hein de. Lei Maria da Penha comentada em uma perspectiva jurídico-feminista. Rio de Janeiro: Lumen Juris, 2011. p. 308.

${ }^{9}$ CASTRO, op. cit. 
urgência da medida pleiteada" é necessária e coerente com os "princípios da devida diligência do Estado e ampla proteção da mulher", posicionamento adotado por Rosane M. Reis Lavigne e Cecília Perlingeiro. ${ }^{10}$

De qualquer maneira, a concessão, inaudita altera pars e por prazo indeterminado, de medidas que restringem a liberdade de locomoção do agressor, somada à morosidade na apresentação da denúncia, constitui um cerceamento de defesa do réu. Sim, pois, nesse caso, o agressor apenas terá a oportunidade de se defender das acusações no curso da ação penal, onde lhe é facultado produzir provas sobre os fatos, a existência do crime, a autoria do fato e da culpabilidade.

Ora, não se pode negar a aplicabilidade das regras do CPP sobre medidas cautelares, aos institutos da Lei Maria da Penha, especialmente ali onde esta foi silente, isto é; na determinação dos requisitos para a imposição liminar de uma medida protetiva. Isto fica especialmente claro se considerarmos que o vigente regramento da matéria no CPP é posterior à lei especial em análise e, portanto, representa a mais recente manifestação do legislador sobre a tutela de urgência no processo penal. Portanto, nos casos em que o contraditório não representar uma concreta ameaça a integridade da vítima, nem prejuízo à sua proteção, ele é medida que se impõe.

\section{A PRISÃO PREVENTIVA COMO MEDIDA PROTETIVA OU SANÇÃO PROCESSUAL}

Além das medidas supracitadas, a Lei Maria da Penha prevê a prisão preventiva em dois

\footnotetext{
${ }^{10}$ LAVIGNE, Rosane M. Reis; PERLINGEIRO, Cecília. Das medidas protetivas de urgência: artigos 18 a 21. In: CAMPOS, Carmen Hein de. Lei Maria da Penha comentada em uma perspectiva jurídico-feminista. Rio de Janeiro: Lumen Juris, 2011. p. 298.

${ }^{11}$ VERAS, Érica Verícia Canuto de Oliveira. As hipóteses de prisão preventiva da lei Maria da Penha na visão do
}

momentos: no seu artigo 20, que trata da prisão como medida exclusivamente cautelar, a ser imposta nos termos das regras gerais previstas nos artigos 312 e seguintes do CPP; e no seu artigo 42, o qual alterou a redação do artigo 313 do CPP, para incluir, no inciso IV, o cabimento da prisão como garantia da eficácia das medidas protetivas de urgência. ${ }^{11}$ Posteriormente, a Lei n 12.403/11, que reformou o sistema de medidas cautelares pessoais no processo penal, revogou tal inciso IV, porém alterou a redação do inciso III do artigo 313 do CPP, para permitir a decretação da prisão preventiva no caso de "o crime envolver violência doméstica e familiar contra a mulher, criança, adolescente, idoso, enfermo ou pessoa com deficiência, para garantir a execução das medidas protetivas de urgência".

Primeiramente, cumpre esclarecer que o instituto da prisão preventiva é uma medida cautelar excepcional que permite a constrição da liberdade do indiciado ou réu, por razões de necessidade, respeitados os requisitos estabelecidos em lei. ${ }^{12}$ Para que se possa decretála, a natureza da infração deve admiti-la, pois alguns delitos, como os culposos, não a admitem. Concomitantemente, deve haver a prova da materialidade e indícios suficientes de autoria (fumus boni juris ou fumus commissi delicti) e ser comprovado perigo que a liberdade do imputado representaria para o bom andamento da instrução criminal, para a aplicação da lei penal ou para a dita "ordem pública", conforme enigmática expressão legal (periculum libertatis).

$\mathrm{Ou}$ seja, além dos requisitos fumus commissi delicti e periculum libertatis, concretizados nas cláusulas do artigo 312 do CPP, deverá o juiz observar os limites de cabimento da

Superior Tribunal de Justiça. Revista Jurídica do Ministério Público do Estado de Minas Gerais, Belo Horizonte, v. 12, n. 21 jul/dez, 2013. p. 178-207.

${ }^{12}$ NUCCI, Guilherme de Souza. Manual de processo penal e execução penal. 11. ed. rev. e atual. Rio de janeiro: Forense, 2014. p. 549. 
prisão preventiva, que estão enumerados no art. 313 do CPP." ${ }^{13}$ Por fim, é necessário o controle jurisdicional prévio, posto que ninguém será preso senão em flagrante delito ou por ordem escrita e fundamentada de autoridade judiciária competente (art. $5^{\circ}$, LXI, da CR/88).

É certo que o parágrafo único do artigo 312 do CPP permite a decretação da prisão preventiva devido ao descumprimento de qualquer das obrigações impostas por força de outras medidas cautelares. Entretanto, o artigo 282, § $6^{0}$ do CPP deixa claro que, apenas em último caso o juiz poderá decretar a prisão preventiva. Em caso de insuficiência ou ineficácia da medida inicialmente imposta, deve o juiz substituí-la ou impor outra em cumulação. Mas a prisão preventiva só se justifica "em último caso". Nesse sentido leciona Aury Lopes Jr:

Sem embargo, pensamos que a interpretação deve ser sistemática e restritiva. Logo, descumprida a medida cautelar diversa imposta, deverá o juiz, em primeiro lugar, buscar a ampliação do controle pela via da acumulação com outra medida cautelar diversa. Somente quando insuficiente a cumulação, poder-se-á cogitar da prisão preventiva e, mesmo assim, quando houver proporcionalidade em relação ao delito imputado. ${ }^{14}$

Assim, a previsão de manejo da prisão preventiva como instrumento coercitivo, em nome da efetividade das demais medidas protetivas, não significa destituí-la de todos os seus fundamentos e requisitos cautelares. Nesse sentido, Rogério Sanches Cunha e Ronaldo Batista Pinto afirmam:

\footnotetext{
${ }^{13}$ LOPES JR., Aury. Prisões Cautelares. 4. ed. rev. atual. e ampl. São Paulo: Saraiva, 2013. p. 97.

${ }^{14}$ Ibid, p. 99. No mesmo sentido, Norberto Avena: “[...] a desobediência não previamente justificada às cautelares impostas autoriza, em qualquer hipótese, sua conversão em prisão preventiva (desde que não seja possível aplicar outra medida alternativa em substituição ou cumulação), ainda que não se trate de situação arrolada no art. 313, sob pena de sua imposição, eventualmente, resultar inócua [...]". AVENA, Norberto. Processo penal esquematizado Material Suplementar. 3. ed. rev. e atual. São Paulo: Editora
}

Insistimos, a nova possibilidade que se inaugura para a decretação da prisão preventiva não pode ser interpretada de forma isolada, impondo, ao revés, que se atente ao preenchimento dos requisitos gerais de toda e qualquer prisão dessa espécie, mencionados no art. 312 do CPP. ${ }^{15}$

Ou seja, a doutrina alerta para a necessidade de cautela para decretar a prisão preventiva por descumprimento de medidas protetivas de urgência. E para além da cautelaridade, não se pode ignorar o requisito da proporcionalidade. Pois existem manifestações delitivas da violência doméstica ou familiar contra a mulher que são incompatíveis com a prisão preventiva. Pois para algumas infrações penais, mesmo em caso de condenação, a pena a ser aplicada seria inferior ao tempo e à gravidade da prisão cautelar. Seria inadequada uma custodia cautelar que impõe ao acusado consequências mais gravosas do que as eventualmente decorrentes, segundo a lei penal, de uma possível condenação.

Assim, rejeita-se amplamente o manejo da prisão preventiva exclusivamente fundado na garantia da execução das medidas protetivas de urgência. ${ }^{16}$ Citando o exemplo do desrespeito ao limite de aproximação da vítima fixado pelo juiz, Rogério Sanches Cunha e Ronaldo Batista Pinto afirmam que:

Caso esse desrespeito venha acompanhado da prática
de algum crime (por exemplo, tentativa de
feminicídio, incêndio, ameaça etc.), ainda se pode
cogitar da decretação da preventiva. Agora, quando
analisado individualmente, isto é, quando seja
apenas essa a conduta imputada ao agente, parece

Método, 2012. p. 12. Contrariamente: CABETTE, Eduardo Luiz Santos. Anotações críticas sobre a lei de violência doméstica e familiar contra a mulher. Jus Navigandi, ISSN 1518-4862, Teresina, ano 11, n. 1146, 21 ago. 2006.

15 CUNHA, Rogério Sanches, PINTO, Ronaldo Batista. Violência Doméstica: Lei Maria da Penha: comentada artigo por artigo. 6. ed. São Paulo: Revista dos Tribunais, 2015. p. 150 .

16 Neste sentido: RANGEL, Paulo. Direito Processual Penal. 24. ed. rev. e atual. São Paulo: Atlas, 2016. p. 829. 
que a medida de exceção é indevida, sob pena de configurar verdadeira inconstitucionalidade. ${ }^{17}$

Entretanto, para o exemplo citado, em que o descumprimento vem acompanhado da prática de um crime, é possível perceber que não é o mero descumprimento da medida protetiva que ensejaria a prisão preventiva, mas sim a prática do crime. Trata-se, pois, de hipótese clássica de decretação desta medida cautelar, nos termos dos artigos 312 e 313 do CPP.

Ressalta-se que a Lei Maria da Penha não criou um novo "periculum libertatis", ${ }^{18}$ ou seja; não criou um novo risco que se pretende tutelar nem dispensou provas do "fumus boni iuris". Desse modo, a decretação da prisão preventiva pelo simples descumprimento de medidas protetivas padece de inconstitucionalidade, por restringir o direito fundamental de liberdade exclusivamente em nome de uma obrigação de fazer ou não fazer, a rigor de natureza cível, em que pese sua cada vez mais reconhecida (felizmente!) acessoriedade em relação ao processo penal.

Qualquer forma de prisão é uma intervenção muito grave. Citando Hobbes, Ferrajoli assim aduz:

\begin{abstract}
A prisão preventiva não é uma pena, mas um ato de hostilidade contra o cidadão, de modo que qualquer dano que faça um homem sofrer, com prisão ou constrição antes que sua causa seja ouvida, além ou acima do necessário para assegurar sua custódia, é contrário à Lei da natureza. ${ }^{19}$
\end{abstract}

Assim sendo, a prisão cautelar deve ser utilizada como ultima ratio, apenas em casos de evidente necessidade, e sua duração deve observar os princípios da proporcionalidade,

\footnotetext{
${ }^{17}$ CUNHA, Rogério Sanches, PINTO, Ronaldo Batista. Violência Doméstica: Lei Maria da Penha: comentada artigo por artigo. 6. ed. São Paulo: Revista dos Tribunais, 2015. p. 151.

${ }^{18}$ LOPES JR., Aury. Prisões Cautelares. 4. ed. rev. atual. e ampl. São Paulo: Saraiva, 2013. p. 101.

${ }^{19}$ FERRAJOLI, Luigi. Direito e razão, ob. cit., p. 443

${ }^{20}$ LOPES JR., op. cit., p. 99.
}

razoabilidade e adequação, sob pena de afronta a direitos constitucionais do acusado. Apesar dos objetivos nobres que motivaram a criação desta Lei, a prisão preventiva tem que respeitar todos os requisitos cautelares. É imperioso haver uma estrita necessidade, que é o concreto perigo à vida ou integridade física da vítima, e a presença de provas de autoria e materialidade suficientes. Por fim, "também se deve atentar aos limites abstratos da pena, para evitar que a prisão preventiva se prolongue por tempo superior àquele da pena privativa de liberdade" a ser aplicada, ao final. ${ }^{20}$

\subsection{Duração da medida preventiva}

Não há na legislação pátria a determinação de um prazo para a prisão preventiva. Desse modo, faz-se "necessário recorrer à construção jurisprudencial sobre qual é a duração razoável da medida cautelar pessoal, tomando como base a disposição constitucional do art. $5^{\circ}$, LXXVIII da $\mathrm{CR} / 88$ ". ${ }^{21}$

Sobre a questão, Rogério Schietti Machado da Cruz pondera que "todos têm o direito de ser julgados em prazo razoável e também o direito de não serem mantidos presos por prazo irrazoável". ${ }^{22}$ O STF vem aplicando o princípio constitucional da razoabilidade na duração da prisão cautelar, mediante análise das peculiaridades de cada caso concreto. Com a reforma do CPP de 2008, referido princípio passou a ser o meio norteador para a fixação do tempo da prisão preventiva e delimitação do excesso em seu prazo. Além disso, a Suprema Corte vem decidindo, reiteradamente, que a conduta das partes no processo, a gravidade do delito e a complexidade da causa são os critérios

${ }^{21}$ BARROS, Flaviane de Magalhães, MACHADO, Felipe Daniel Amorim. Prisão e Medidas Cautelares: nova reforma do Processo Penal - Lei n.12.403/2011. Del Rey, 2011. p. 202.

${ }^{22}$ CRUZ, Rogério Schietti Machado da. Prisão Cautelar: dramas, princípios e alternativas. Rio de Janeiro: Lúmen Juris, 2006. p. 107. 
norteadores da análise que aufere a razoabilidade do prazo da prisão preventiva em cada caso. ${ }^{23}$

De todo modo, a proporcionalidade impõe que a prisão preventiva não exceda os limites da pena mínima prevista para o delito e considere, ainda, os benefícios da execução penal, a possibilidade de concessão de penas alternativas ou do "sursis". ${ }^{24}$

Nas palavras de Aury Lopes Jr.:

Significa dizer que o juiz deve sempre atentar para a relação existente entre a eventual sanção cominada ao crime em tese praticado e aquela imposta em sede de medida cautelar, para impedir que o imputado seja submetido a uma medida cautelar que se revele mais gravosa do que a sanção porventura aplicada ao final. É inadmissível submeter alguém a uma prisão cautelar quando a sanção penal aplicada não constitui pena privativa de liberdade. ${ }^{25}$

A prisão preventiva possui um caráter de provisionalidade, nos termos do artigo $282, \S \S 4^{\circ}$ e $5^{\circ}$ do CPP, de modo que deve ser concedida apenas em casos de estrita necessidade e revogada quando cessado o perigo decorrente da manutenção do acusado em liberdade, chamado periculum libertatis, ou quando refutada a materialidade ou autoria do crime, também conhecida como fumus commissi delicti.

$\mathrm{Na}$ sistemática da "Lei Maria da Penha", a prisão preventiva de todo modo se destaca como uma medida evidentemente acessória à persecução criminal do episódio de violência, que não prescinde da instauração de um inquérito ou um processo penal, e que impõe a esses procedimentos uma tramitação relativamente célere, razoavelmente obediente à media dos prazos legais previstos para esses procedimentos. E certamente, a prisão não resiste à extinção da punibilidade ou ao desinteresse da vítima pela persecução penal do fato.

\footnotetext{
${ }^{23}$ PEREIRA, Viviane de Freitas; MEZZALIRA, Ana Carolina. O Supremo Tribunal Federal e o prazo razoável da prisão preventiva. In: Âmbito Jurídico, Rio Grande, XIII, n. 78, jul. 2010.
}

\subsection{Da (in)aplicabilidade da prisão preventiva em casos de contravenção penal e crime punível com pena de detenção: doutrina, jurisprudência e caso da Divisão de Assistência Judiciária da UFMG}

Além dos requisitos supracitados, é importante ressaltar que a prisão preventiva por descumprimento de medidas protetivas supõe expressamente o cometimento de um "crime. Ocorre que, dentro das possibilidades de violência doméstica e familiar, encontram-se alguns comportamentos que configuram meras contravenções penais. Observa-se que a referida disposição legal não menciona as contravenções penais como hipótese de prisão preventiva. A própria interpretação literal do dispositivo afasta o cabimento da prisão preventiva no caso de contravenções penais. Uma interpretação extensiva deste não condiz com os princípios basilares do processo penal constitucional.

Ademais, destaca-se que as contravenções penais são puníveis no máximo com prisão simples, em que o cumprimento da pena ocorre sem rigor penitenciário, nos regimes aberto ou semiaberto. Do mesmo modo, nos crimes puníveis com pena de detenção, também não se admite que o início do cumprimento da pena em regime fechado. A pena detenção, em regra, é cumprida nos regimes semiaberto ou aberto, em estabelecimentos distintos dos presídios, quais sejam: as colônias agrícolas, industriais ou similares, no regime semi-aberto, ou em casas de albergado, no regime aberto.

Ora, desafia o postulado da proporcionalidade qualquer possibilidade de prisão preventiva, quando a sanção prevista para o fato punível não envolve o regime fechado. Não

\footnotetext{
${ }^{24}$ NUCCI, Guilherme de Souza. Manual de processo penal e execução penal. 11. ed. rev. e atual. Rio de janeiro:
} Forense, 2014. p. 551

${ }^{25}$ LOPES JR., op. cit., p. 47. 
obstante, são muitos os julgados ${ }^{26}$ que admitem a prisão preventiva, mesmo quando o crime pelo qual o acusado responde é punível com detenção. Fundam-se em circunstâncias especiais relacionadas à situação de violência doméstica e com o fim de assegurar o cumprimento das medidas protetivas. Por exemplo, em relação à utilização da prisão preventiva em caso de crimes apenados com detenção, há decisão expressa do STJ no sentido de que o CPP “... prevê a possibilidade de decretação de prisão preventiva nessas hipóteses, em circunstâncias especiais, com vistas a garantir a execução de medidas protetivas de urgência". ${ }^{27}$

Porém, conforme exposto no item 4, entendemos que não basta o mero descumprimento das medidas protetiva para que a prisão preventiva seja decretada, sendo necessário o cumprimento de todos os requisitos supracitados de cabimento. Na mesma linha de raciocínio não seria possível defender outra ideia senão a impossibilidade de decretação da prisão preventiva em crimes punidos com detenção ou com prisão simples.

A estas hipóteses acrescente-se a dos crimes puníveis com pena não superior a quatro anos que não envolvam violência física ou psicológica (grave ameaça). Pois nestas hipóteses, em geral é cabível a substituição da pena privativa de liberdade eventualmente aplicada por penas restritivas de direitos ou multa, prevista no artigo 44 do $\mathrm{CP}$, o que torna igualmente desarrazoada a prisão processual.

Contudo percebe-se na prática que, infelizmente, tem sido decretada a prisão

\footnotetext{
${ }^{26}$ BRASIL. Superior Tribunal de Justiça. Habeas Corpus $n^{o}$ 132.379/BA. Relatora Min. Laurita Vaz. Julgado em: 26/05/2009. Publicado em: 12/06/2009. Disponível em: $<$ https://ww2.stj.jus.br/processo/revista/documento/mediad $\mathrm{o} /$ ?componente $=$ ITA\&sequencial $=886882 \&$ num_registro $=$ $200900569696 \&$ data $=20090615 \&$ formato $=P D F>$. Acesso em: 25 jun 2017; BRASIL. Superior Tribunal de Justiça. Recurso em Habeas Corpus $n^{\circ}$ 57.027/AL. Rel. Ministro Rogério Schietti Cruz. Julgado em: 16/04/2015. Publicado em: 27/04/2015. Disponível em:
}

preventiva pelo descumprimento de medidas protetivas inclusive nos casos em que a agressão que ensejou a concessão de tais medidas venha a ser uma infração de menor potencial ofensivo, um crime punível com mera detenção, ou até uma contravenção penal punível apenas com prisão simples.

A Divisão de Assistência Judiciária da UFMG acompanhou um caso que representa a problemática acima abordada: o assistido foi acusado de cometer a contravenção penal de perturbação do sossego, prevista no art. 65 da LCP, cuja pena máxima cominada em abstrato é de dois meses de prisão simples. Medidas protetivas foram concedidas em benefício de sua avó, de 77 anos de idade, dentre as quais, o afastamento do lar e da vítima. O assistido, porém, teria desobedecido as restrições que lhe foram impostas, armando uma barraca e acampando ao lado do portão de entrada da moradia da vítima. Isto levando o juiz a decretar sua prisão preventiva, por descumprimento de medidas protetivas de urgência. Além disso, o assistido foi denunciado pelo crime previsto no art. 359 do $\mathrm{CP}$, que tipifica o delito de desobediência à decisão judicial sobre perda ou suspensão de direito.

Foi impetrado um Habeas Corpus, pleiteando-se a liberdade do suposto agressor, sendo que a revogação dessa prisão só foi determinada em sede de recurso, pelo Superior Tribunal de Justiça, após o paciente permanecer preso durante mais de 5 meses. Ora, ele só poderia ser punido com no máximo 2 meses de prisão simples, pela contravenção penal que lhe foi

<https://ww2.stj.jus.br/processo/revista/inteiroteor/?num_r egistro=201500407953\&dt_publicacao=27/04/2015 > . Acesso em: 25 jun. 2017.

${ }^{27}$ BRASIL. Superior Tribunal de Justiça. Recurso em Habeas Corpus $n^{\circ}$ 46.362/MS. Rel. Ministra Laurita Vaz, Quinta Turma. Julgado em: 27/05/2014. Publicado em: 03/06/2014. Disponível em: <https://ww2.stj.jus.br/processo/revista/inteiroteor/?num_r egistro=201400629120\&dt_publicacao=03/06/2014 > .

Acesso em: 25 jun. 2017. 
imputada! E ainda que viesse a ser condenado pelo crime do art. 359 do CP, cuja pena mínima é de 3 meses, a soma desta com a da contravenção jamais seria superior ao tempo em que ficou preso preventivamente, em situação análoga à do regime fechado. Verificou-se, pois, a toda evidência o descabimento da prisão preventiva. Pois conforme decidiu o ilustrado Relator no acórdão que julgou definitivamente o writ:

\begin{abstract}
Segundo o princípio da homogeneidade corolário do princípio da proporcionalidade, mostra-se ilegal a prisão cautelar, quando essa medida for mais gravosa do que a própria sanção a ser aplicada em caso de eventual condenação. Vale dizer, o Juiz não pode impor ao réu um encarceramento com intensidade mais grave do que aquele que lhe seria infligido caso fosse realmente considerado culpado, sob pena de se tornar a medida cautelar mais punitiva do que o que se espera com o resultado final do processo. É dizer, se o paciente pode ser punido com no máximo 2 meses de prisão simples pela infração penal que lhe é imputada, não pode permanecer preso, a título de cautela preventiva, por mais do que esse período (já está preso há mais de 5 meses). Mesmo se incluido o crime do art. 359 do CP, a pena mínima é de 3 meses, o que, somada ao máximo da contravenção, resultaria ainda total inferior ao tempo em que já se encontra preso. ${ }^{28}$
\end{abstract}

Portanto, mesmo no caso de infração praticada no contexto de violência doméstica, em sendo mera contravenção, crime punível com pena de detenção ou que admita a substituição de pena, não cabe a decretação da prisão preventiva pelo descumprimento das medidas protetivas de urgência. $^{29}$

Qualquer decisão em contrário fere o princípio da proporcionalidade. E no que diz respeito ás contravenções, malfere também o princípio da legalidade, visto que a lei não

28 BRASIL. Superior Tribunal de Justiça. Recurso em Habeas Corpus $n^{\circ} 75.395 / M G$. Rel. Ministro Rogério Shietti Cruz. Julgado em: 09/08/2016. Publicado em: 13/09/2016.

Disponível

em:

<https://ww2.stj.jus.br/processo/monocraticas/decisoes/?n um_registro=201602070313\&dt_publicacao=17/08/2016>. Acesso em: 25 jun. 2017.

29 Assim também CUNHA, Rogério Sanches, PINTO, Ronaldo Batista. Violência Doméstica: Lei Maria da Penha: comentada artigo por artigo. 6. ed. São Paulo: menciona as contravenções penais, mas, tão somente, supostos crimes, como hipóteses de prisão preventiva. Outros precedentes do STJ avalizam esta conclusão, como a que se transcreve:

[...] 3. Embora o juiz singular tenha fundamentado concretamente a necessidade da custódia cautelar para garantir a execução das medidas protetivas de urgência (artigo 313, III, do Código de Processo Penal), o paciente está sendo acusado da suposta prática do crime de ameaça - cuja reprimenda cominada em abstrato é de detenção, de 1 a 6 meses, ou multa -, bem como de ter cometido vias de fato cuja pena abstratamente prevista é de prisão simples, de 15 dias a 3 meses, ou multa -, de maneira que se mostra ilegal a prisão cautelar, à luz do princípio da homogeneidade entre cautela e pena, máxime quando a segregação do paciente perdura há mais de 8 meses. ${ }^{30}$

\section{CRIME DE DESOBEDIÊNCIA POR DESCUMPRIMENTO DAS MEDIDAS PROTETIVAS DE URGÊNCIA}

Partindo da premissa de que a prisão preventiva não é cabível em face de contravenções penais, crimes puníveis com detenção, crimes de menor potencial ofensivo e nos crimes em geral que autorizam a substituição de pena, quando o agente preencha os requisitos, impõe-se a nós a questão de qual consequência coercitiva seria cabível no caso do descumprimento de medidas protetivas. Primeiramente, destaca-se que é possível a substituição por outras medidas protetivas ou a decretação de novas medidas, em cumulação. Além dessas, o artigo 22, § 4ํㅡㄹ da Lei Maria da Penha, prevê a possibilidade de usar de medidas

Revista dos Tribunais, 2015. p. 147, “pois a pena a ser aplicada, no futuro, seria insuficiente para "cobrir" o tempo de prisão cautelar".

${ }^{30}$ BRASIL. Superior Tribunal de Justiça. Recurso em Habeas Corpus $n^{\circ}$ 46.362/MS. Rel. Ministra Laurita Vaz, Quinta Turma. Julgado em: 27/05/2014. Publicado em: 03/06/2014. Disponível em: <https://ww2.stj.jus.br/processo/revista/inteiroteor/?num_r egistro=201400629120\&dt_publicacao=03/06/2014 > .

Acesso em: 25 jun. 2017. 
previstas no Código de Processo Civil. Assim a tutela específica, por meio da fixação de multa com a finalidade forçar o cumprimento de uma obrigação de fazer. $\mathrm{Na}$ esfera penal, o descumprimento das medidas protetivas ordenadas por um juiz configura crime de desobediência.

Não obstante, tendo em vista a prática evidentemente injusta de se cumular a prisão preventiva do agressor recalcitrante, com um processo penal por desobediência, a jurisprudência do STJ fixou o entendimento de que o descumprimento de medidas protetivas não é punível como crime de desobediência, em face da previsão expressa no CPP de que a hipótese já enseja, como sanção, a decretação da prisão preventiva. $^{31}$

Tal jurisprudência do STJ visa evitar que uma mesma conduta, qual seja, o descumprimento das medidas protetivas, provoque uma dupla punição: a decretação da prisão do agente e as penas correspondentes ao delito de desobediência. Trata-se, assim, de uma interpretação que busca afastar o "bis in idem", ou seja, a dupla penalização do descumpridor. Desse modo, a tese do STJ, em atenção aos princípios da proporcionalidade e intervenção penal mínima, estabelece que o descumprimento de medidas protetivas não é punível como crime de

31 BRASIL. Superior Tribunal de Justiça. Agravo Regimental no Agravo em Recurso Especial no 699.637/SP, Rel. Ministro Reynaldo Soares da Fonseca, Quinta Turma. Julgado em 27/04/2017, Publicado em: 05/05/2017. Disponível

em:

<https://ww2.stj.jus.br/processo/revista/inteiroteor/?num_r egistro=201501012657\&dt_publicacao=05/05/2017>.

Acesso em: 25 jun. 2017; BRASIL. Superior Tribunal de Justiça. Agravo Regimental no Habeas Corpus $n^{o}$ 298.202/RS. Rel. Ministro Antonio Saldanha Palheiro, Sexta Turma, julgado em 01/09/2016, DJe 12/09/2016) Disponível

em:

<https://ww2.stj.jus.br/processo/revista/inteiroteor/?num_r egistro=201401595873\&dt_publicacao=12/09/2016>.

Acesso em: 25 jun. 2017; BRASIL. Superior Tribunal de Justiça. Agravo Regimental no Habeas Corpus $n^{o}$ 298.202/RS. Rel. Ministro Antônio Saldanha Palheiro, Sexta Turma. Julgado em: 01/09/2016. Publicado em: desobediência (art. 330 do CP) porque a aplicação dessa incriminação dependeria não só do descumprimento de ordem judicial, mas também da inexistência de previsão de sanção específica, de modo que prevalecerá a decretação da prisão preventiva.

Apesar do entendimento do STJ, esta matéria não está pacificada nos Tribunais. Há inúmeras decisões contrárias, nas quais se admite o delito de desobediência por descumprimento de medidas protetivas. Tais decisões, muitas vezes entendem ser possível a cumulação da prisão preventiva com a condenação pelo crime de desobediência, sob o argumento de que, excluindo-se a incriminação, estar-se-ia incentivando a continuidade de agressões no contexto de violência doméstica.

Os julgados que admitem a condenação pelo crime de desobediência de medida protetivas oscilam quanto à capitulação de tal conduta, ora recorrendo ao tipo do artigo $330,{ }^{32}$ ora ao tipo do artigo $359^{33}$, ambos do Código Penal. Os que entendem ser a hipótese do artigo 359 do CP, argumentam que a decisão desobedecida é uma determinação judicial que suspende ou priva o agente do exercício de alguns de seus direitos. ${ }^{34}$ Aduzem, ainda, que o artigo 359 do Código Penal, por ser um tipo específico para desobediência de

12/09/2016.

Disponível

em:

<https://ww2.stj.jus.br/processo/monocraticas/decisoes/?n um_registro $=201401595873 \& d t \_p u b l i c a c a o=04 / 08 / 2016>$. Acesso em: 25 jun. 2017.

32 Art. 330 - Desobedecer a ordem legal de funcionário público: Pena - detenção, de quinze dias a seis meses, e multa.

${ }^{33}$ Art. 359 - Exercer função, atividade, direito, autoridade ou múnus, de que foi suspenso ou privado por decisão judicial: Pena - detenção, de três meses a dois anos, ou multa.

${ }^{34}$ BRASIL. Superior Tribunal de Justiça. Habeas Corpus $n^{o}$ 220392/RJ. Rel. Ministro Jorge Mussi, Quinta Turma. Julgado em: 25/02/2014. Publicado em: 10/03/2014. Disponível em: <https://ww2.stj.jus.br/processo/revista/inteiroteor/?num_r egistro=201102353150\&dt_publicacao=10/03/2014>.

Acesso em: 25 jun. 2017. 
decisão judicial, prevaleceria sobre a tipo penal do artigo 330 do CP.

Já os julgados ${ }^{35}$ que aplicam o artigo 330 do $\mathrm{CP}$, argumentam que o crime do art. 359 do $\mathrm{CP}$ não se configura na hipótese por falta de uma violação à vedação de exercício da função, atividade, direito, autoridade ou múnus. Ademais, aduzem que o delito tipificado no art. 359 do CP pressupõe, além da habitualidade, a existência de decisão judicial que se revista de estabilidade e se amolde às hipótese do art. 92, I a III, do CP, que tratam dos efeitos extrapenais da condenação (perda de cargo, função pública ou mandato eletivo; a incapacidade para o exercício do pátrio poder, tutela ou curatela, a inabilitação para dirigir veículo, quando utilizado como meio para a prática de crime doloso, etc.).

Independentemente do tipo penal que se aplique, em ambos os casos (330 e 359, CP) a pena cominada possibilita a transação penal. Vale dizer que a esses crimes não são alcançados pela vedação do artigo 41 da Lei Maria da Penha, ${ }^{36}$ pois não se tratam de crimes contra a mulher: um é contra a administração pública e o outro contra a administração da justiça. Entretanto, apesar de haver julgados que condenam pela prática do crime de desobediência, oscilando entre o 330 e o 359 do CP, cumpre ressaltar que para a jurisprudência majoritária o descumprimento da ordem judicial que defere medida protetiva de urgência com base na Lei Maria da Penha deve ter por única consequência jurídica a prisão preventiva, prevista no art. 313, III, do CPP.

Embora tal entendimento, a princípio, pareça ser justo e favorável ao réu, ele parte de falsas premissas e elege uma medida cautelar desproporcional, em vez de aplicar ao caso a

\footnotetext{
35 BRASIL. Tribunal de Justiça do Rio Grande do Sul. Recurso Crime $n^{\circ} 71004225611$. Turma Recursal Criminal. Relator Edson Jorge Cechet. Julgado em: 29/04/2013. Publicado em: 30/04/2013. Disponível em: $<$ http://www.tjrs.jus.br/busca/search?q=\&proxystylesheet= tjrs_index\&client $=$ tjrs_index $\&$ filter $=0 \&$ getfields $=* \& a b a=j$ uris\&entsp $=$ a_politica-

site $\& w c=200 \& w c \_m c=1 \& o e=U T F-8 \& i e=U T F-$
}

incriminação de gravidade relativamente baixa, estabelecida na lei. Primeiramente, supõe equivocadamente que a prisão preventiva prevista no artigo 312, parágrafo único e 313, III, do CPP não pressupõe cautelaridade e pode ser decretada exclusivamente como sanção processual; depois, supõe equivocadamente que a aplicação de uma dita sanção processual excluiria a eficácia de uma norma penal incriminadora, numa evidente inversão de valores. Ora, o processo serve à aplicação da norma penal; não à sua ineficácia. E se uma medida processual é incompatível com o tratamento penal da matéria, é a norma processual que deve ser afastada, por sua inadequação aos seus fins, não a norma penal, cuja concretização legítima é a própria finalidade do processo.

Ressalta-se que é evidentemente preferível ao suposto agressor rebelde, responder por crime de desobediência, ao descumprir medidas protetivas, do que sofrer prisão preventiva. Pois nos termos da lei, a desobediência, em qualquer das suas modalidades, admite transação penal, suspensão condicional do processo, substituição de pena e, na pior das hipóteses pena privativa de liberdade em regime aberto. Como então se pode aceitar como correto, próprio de uma corte Superior que tem por missão constitucional proteger a lei federal, o afastamento das penas da desobediência, em troca de uma intolerável sanção processual, mal travestida de medida cautelar, evidentemente desproporcional em face dos próprios artigos 330 e 359 do CP? Desde quando se pode admitir que medida cautelar processual derroga norma penal? Trata-se de um desatino ainda não denunciado, já que aos olhos do preso que responde por desobediência, esse entendimento do STJ soa como uma dádiva.

$8 \& u d=1 \&$ sort=date $\% 3 \mathrm{AD} \% 3 \mathrm{AS} \% 3 \mathrm{Ad} 1 \&$ as_qj=\&site $=$ em entario\&as_epq=\&as_oq=\&as_eq $=\&$ partialfields $=$ n $\% 3 \mathrm{~A} 7$ $1004225611 \&$ as_q=+\#main_res_juris $>$. Acesso em: 25 jun. 2017.

36 “Aos crimes praticados com violência doméstica e familiar contra a mulher, independentemente da pena prevista, não se aplica a Lei no 9.099, de 26 de setembro de 1995." 
Dádiva que, em verdade, apenas disfarça e legitima a injustiça maior, da prisão preventiva.

Defende-se, pois, que não sendo eficientes nenhuma das medidas previstas na Lei Maria da Penha, se a agressão praticada não autorizar, por sua diminuta gravidade, a prisão preventiva, a conduta de desobedecer à ordem judicial que fixou as medidas protetivas de urgência deve ser punida como desobediência, capitulada no art. 330 ou 339 do Código Penal, conforme o caso. Após um processo penal que respeite os direitos ao contraditório, à ampla defesa e à individualização da pena, será possível sancionar o descumpridor de ordem judicial. $\mathrm{O}$ que não ocorre quando se reprime o descumprimento das medidas protetivas com prisão preventiva. Aqui o que se tem é uma punição desproporcional e sem processo.

Entende-se que isso significa desrespeitar os princípios da legalidade, transformando-se medida cautelar em sanção; da proporcionalidade e da obrigatoriedade da ação penal, por admitir-se uma pena sem processo; e da culpabilidade, por estar se aplicando uma "pena" que não visa reprimir o injusto praticado, mas evitar possíveis infrações futuras.

\section{CONCLUSÃO}

No presente trabalho, foram analisados características e procedimentos da Lei $\mathrm{n}^{\mathbf{o}}$ 11.340/06, que trouxe diversas inovações ao direito brasileiro, dentre as quais se destaca a possibilidade de concessão de medidas protetivas de urgência específicas para a proteção da vítima de violência doméstica.

Em que pese sua inegável importância simbólica e prática, a Lei Maria da Penha traz diversas questões controversas, referentes à sua aplicação prática, que concretizam o permanente embate entre a máxima proteção da integridade física da vítima, e o respeito ao devido processo legal, a ampla defesa e contraditório, devidos ao suposto agressor.

O primeiro ponto controvertido apontado é a possibilidade de concessão das medidas de urgência previstas na referida Lei inaudita altera pars. De fato, a aplicação de tais medidas sem prévio contraditório em todo e qualquer suposto caso de violência doméstica contradiz o devido processo legal. A concessão de medidas protetivas sem prévia defesa do acusado só se justifica quando haja nítido risco de ineficácia da medida, caso ela não seja imediatamente imposta, nos moldes do $\S 4^{\circ}$ do artigo 286, do CPP.

Outra questão controversa é a utilização da prisão preventiva para coibir supostas práticas de crimes apenados com detenção, ou mesmo de contravenções penais. $E$, não obstante as respeitáveis ponderações daqueles que sustentam posicionamentos contrários, a aplicação da prisão preventiva, nesses casos, é incoerente com a sistemática do processo constitucional. Pensar de forma distinta significa admitir a possibilidade do acusado ser punido, "provisoriamente", com uma sanção mais grave que aquela efetivamente prevista para o crime ou contravenção penal supostamente praticado por ele, o que afronta os princípios da razoabilidade e homogeneidade entre cautela e pena.

Por fim, rejeita-se a tese de que a prisão preventiva seja a nova resposta do sistema penal para o descumpridor de medida protetiva, em prejuízo da sua punibilidade por desobediência. Pois não se pode substituir uma pena criminal por uma sanção processual, muito menos quando essa sanção seja desproporcional à pena. Tal pretensão significa punir sem processo, portanto sem culpa, e com penas diversas da que a lei prevê para o crime. Um absurdo completo, que sob o cândido pretexto de coibir $o$ bis in idem, legitima a terrível injustiça de afastar um crime de menor potencial ofensivo em favor da mais gravosa das medidas cautelares processuais. 


\section{REFERÊNCIAS}

AVENA, Norberto. Processo penal esquematizado - Material Suplementar. 3. ed. rev. e atual. São Paulo: Editora Método, 2012.

BARROS, Flaviane de Magalhães, MACHADO, Felipe Daniel Amorim. Prisão e Medidas Cautelares: nova reforma do Processo Penal - Lei n.12.403/2011. Del Rey, 2011.

BRASIL. Código de Processo Penal. Decreto-Lei no 3.689, de 3 de outubro de 1941. Disponível em: <http://www.planalto.gov.br/ccivil_03/decreto-lei/Del3689Compilado.htm>. Acesso em: 17 jun. 2017.

BRASIL. Tribunal de Justiça do Rio Grande do Sul. Recurso Crime $n^{\circ} 71004225611$. Turma Recursal Criminal. Relator Edson Jorge Cechet. Julgado em: 29/04/2013. Publicado em: 30/04/2013. Disponível em:

$<$ http://www.tjrs.jus.br/busca/search?q=\&proxystylesheet=tjrs_index\&client=tjrs_index\&filter=0\&ge tfields $=* \& a b a=j u r i s \&$ entsp $=a \_$politica-site $\& w c=200 \& w c \_m c=1 \& o e=U T F-8 \& i e=U T F-$

$8 \& u d=1 \&$ sort=date $\% 3 \mathrm{AD} \% 3 \mathrm{AS} \% 3 \mathrm{Ad} 1 \&$ as_qj=\&site=ementario\&as_epq=\&as_oq=\&as_eq=\&parti alfields=n\%3A71004225611\&as_q=+\#main_res_juris $>$. Acesso em: 25 jun. 2017.

BRASIL. Superior Tribunal de Justiça. Agravo Regimental no Agravo em Recurso Especial $n^{o}$ 699.637/SP, Rel. Ministro Reynaldo Soares da Fonseca, Quinta Turma. Julgado em 27/04/2017, Publicado em: 05/05/2017. Disponível em: <https://ww2.stj.jus.br/processo/revista/inteiroteor/?num_registro=201501012657\&dt_publicacao=05 /05/2017>. Acesso em: 25 jun. 2017.

BRASIL. Superior Tribunal de Justiça. Agravo Regimental no Habeas Corpus $n^{\circ}$ 298.202/RS. Rel. Ministro Antonio Saldanha Palheiro, Sexta Turma, julgado em 01/09/2016, DJe 12/09/2016) Disponível

em:

<https://ww2.stj.jus.br/processo/revista/inteiroteor/?num_registro=201401595873\&dt_publicacao=12 /09/2016>. Acesso em: 25 jun. 2017.

BRASIL. Superior Tribunal de Justiça. Agravo Regimental no Habeas Corpus $n^{\circ}$ 298.202/RS. Rel. Ministro Antônio Saldanha Palheiro, Sexta Turma. Julgado em: 01/09/2016. Publicado em: $12 / 09 / 2016$.

Disponível

em:

<https://ww2.stj.jus.br/processo/monocraticas/decisoes/?num_registro=201401595873\&dt_publicaca o=04/08/2016>. Acesso em: 25 jun. 2017.

BRASIL. Superior Tribunal de Justiça. Agravo Regimental no Habeas Corpus $\mathrm{n}^{\circ}$ 298.202/RS Rel. Ministro Antônio Saldanha Palheiro, Sexta Turma. Julgado em: 01/09/2016. Publicado em: $12 / 09 / 2016$.

Disponível

em:

<https://ww2.stj.jus.br/processo/monocraticas/decisoes/?num_registro=201602070313\&dt_publicaca o=17/08/2016> Acesso em: 25 jun. 2017.

BRASIL. Superior Tribunal de Justiça. Habeas Corpus $n^{o}$ 220392/RJ. Rel. Ministro Jorge Mussi, Quinta Turma. Julgado em: 25/02/2014. Publicado em: 10/03/2014. Disponível em: $<$ https://ww2.stj.jus.br/processo/revista/inteiroteor/?num_registro=201102353150\&dt_publicacao $=10$ /03/2014> Acesso em: 25 jun. 2017. 
BRASIL. Superior Tribunal de Justiça. Recurso em Habeas Corpus $n^{o}$ 46.362/MS. Rel. Ministra Laurita Vaz, Quinta Turma. Julgado em: 27/05/2014. Publicado em: 03/06/2014. Disponível em: <https://ww2.stj.jus.br/processo/revista/inteiroteor/?num_registro=201400629120\&dt_publicacao=03 /06/2014> Acesso em: 25 jun. 2017

BRASIL. Superior Tribunal de Justiça. Recurso em Habeas Corpus $n^{o}$ 46.362/MS. Rel. Ministra Laurita Vaz, Quinta Turma. Julgado em: 27/05/2014. Publicado em: 03/06/2014. Disponível em: $<$ https://ww2.stj.jus.br/processo/revista/inteiroteor/?num_registro=201400629120\&dt_publicacao=03 /06/2014> Acesso em: 25 jun. 2017

BRASIL. Superior Tribunal de Justiça. Recurso em Habeas Corpus $n^{o}$ 57.027/AL. Rel. Ministro Rogério Schietti Cruz. Julgado em: 16/04/2015. Publicado em: 27/04/2015. Disponível em: $<$ https://ww2.stj.jus.br/processo/revista/inteiroteor/?num_registro=201500407953\&dt_publicacao=27 /04/2015>. Acesso em: 25 jun. 2017.

BELLOQUE, Juliana Garcia. Das medidas protetivas que obrigam o agressor - artigos 22. In: CAMPOS, Carmen Hein de. Lei Maria da Penha comentada em uma perspectiva jurídico-feminista. Rio de Janeiro: Lumen Juris, 2011. Disponível em: <https://www.cladem.org/images/pdfs/litigio/producciones-y-materiales/publicaciones/lei-maria-dapenha.pdf> Acesso em: 17 jun. 2017.

CABETTE, Eduardo Luiz Santos. Anotações críticas sobre a lei de violência doméstica e familiar contra a mulher. Jus Navigandi, ISSN 1518-4862, Teresina, ano 11, n. 1146, 21 ago. 2006. Disponível em: <https://jus.com.br/artigos/8822>. Acesso em: 23 jun. 2017.

CASTRO, Fabiana Oliveira Bastos. O Contraditório prétivo na decretação das medidas cautelares previstas na Lei Maria da Penha: uma perspectiva evolutiva. In: XXIV CONGRESSO NACIONAL DO CONPEDI, 19., 2015, Florianópolis. Anais Processo, Jurisdição e efetividade da Justiça I. Florianópolis: CONPEDI, 2015.2 Disponível em: <http://www.conpedi.org.br/publicacoes/66fs1345/5mojv6ev/gn8SPiOlrYvcnbL8.pdf>. Acesso em: 16 jun. 2017.

COELHO, Pedro. Princípio da Homogeneidade e as prisões cautelares. Disponível em: <http://blog.ebeji.com.br/principio-da-homogeneidade-e-as-prisoes-cautelares/>. Acesso em: $02 \mathrm{dez}$. 2016.

COMISSÃO Interamericana de Direitos Humanos. Caso 12.051. Relatório $n^{o}$ 54/01. Disponível em: <http://www.sbdp.org.br/arquivos/material/299_Relat\%20n.pdf>. Acesso em: 25 jun. 2017.

COMISSÃO Interamericana de Direitos Humanos. Relatório anual 2000 / Relatório $n^{o}$ 54/01. Brasil, 04 abr. 2001.

CRUZ, Rogério Schietti Machado da. Prisão Cautelar: dramas, princípios e alternativas. Rio de Janeiro: Lúmen Juris, 2006.

CUNHA, Rogério Sanches, PINTO, Ronaldo Batista. Violência Doméstica: Lei Maria da Penha: comentada artigo por artigo. 6. ed. São Paulo: Revista dos Tribunais, 2015.

DIAS, Maria Berenice. Lei Maria da Penha, afirmação da igualdade. Âmbito Jurídico, Rio Grande, X, n. 46, out. 2007. Disponível em: <http://www.ambito- 
juridico.com.br/site/index.php?n_link=revista_artigos_leitura\&artigo_id=2397>. Acesso em: 27 nov. 2016.

DIAS, Maria Berenice. A Lei Maria da Penha na Justiça: a efetividade da Lei 11.340/2006 de combate à violência doméstica e familiar contra a mulher. São Paulo: Revista dos Tribunais, 2007.

FERRAJOLI, Luigi. Derecho y razón. 3. ed. Tradução de Perfecto Andrés Ibañez. Madrid: Trotta, 1998.

FERRAJOLI, Luigi. Direito e razão: teoria do garantismo penal. Trad. da 6. ed. italiana por Ana Paula Zomer et al. São Paulo: Revista dos Tribunais, 2002.

LAVIGNE, Rosane M. Reis; PERLINGEIRO, Cecília. Das medidas protetivas de urgência: artigos 18 a 21. In: CAMPOS, Carmen Hein de. Lei Maria da Penha comentada em uma perspectiva jurídicofeminista. Rio de Janeiro: Lumen Juris, 2011. Disponível em: <https://www.cladem.org/images/pdfs/litigio/producciones-y-materiales/publicaciones/lei-maria-dapenha.pdf $>$. Acesso em: 17 jun. 2017.

LOPES JR., Aury. Prisões Cautelares. 4. ed. rev. atual. e ampl. São Paulo: Saraiva, 2013.

NUCCI, Guilherme de Souza. Manual de processo penal e execução penal. 11. ed. rev. e atual. Rio de janeiro: Forense, 2014.

OLIVEIRA, Eugênio Pacelli de. Curso de processo penal. 15.ed. rev. e atual. Rio de Janeiro: Lumen Juris, 2011.

PEREIRA, Viviane de Freitas; MEZZALIRA, Ana Carolina. O Supremo Tribunal Federal e o prazo razoável da prisão preventiva. In: Âmbito Jurídico, Rio Grande, XIII, n. 78, jul. 2010. Disponível em: $<$ http://www.ambito-

juridico.com.br/site/index.php?artigo_id=7810\&n_link=revista_artigos_leitura>. Acesso em: $01 \mathrm{dez}$. 2016.

PRESSER, Tiago. Medidas protetivas às vítimas de violência doméstica. Disponível em: <http://www.direitonet.com.br/artigos/exibir/8563/Medidas-protetivas-as-vitimas-de-violenciadomestica>. Acesso em: 01 dez. 2016.

PORTO, Pedro Rui da Fontoura. Violência doméstica e familiar contra a mulher: análise crítica e sistêmica. Porto Alegre: Livraria do Advogado Editora, 2007.

RANGEL, Paulo. Direito Processual Penal. 24. ed. rev. e atual. São Paulo: Atlas, 2016.

SOARES, Bárbara M. Enfrentando a violência contra a mulher. 2007. Disponível em: <http://www.mpdft.mp.br/portal/index.php/conhecampdft-menu/nucleos-menu/ nucleo-de-generopro-mulher-menu/209-nucleos/nucleo-de-genero/639-comentarios-a-lei-maria-da-penha>. Acesso em: 20 abr. 2014.

SECRETARIA DE ESTADO DE SEGURANÇA PÚBLICA. Cartilha "Conhecendo a Lei $n^{o}$ 11.340/06 - Lei Maria da Penha”. Edição 01 mai. 2008. Disponível em: <http://www.pc.ac.gov.br/wps/wcm/connect/28e0df004a9f19f98420959841167f48/conhecendo_+ma ria_penha.pdf?MOD=AJPERES>. Acesso em: 27 nov. 2016. 
TAVARES, Márcia Santana; SARDENBERG, Cecília M. B.; GOMES, Márcia Queiroz de C. Feminismo, Estado e Políticas de Enfrentamento à Violência contra mulheres: monitorando a Lei Maria da Penha. Labrys Estudos Feministas, Florianópolis: UFSC, jun./dez, 2011. Disponível em: <https://www.labrys.net.br/labrys20/brasil/lei\%20MP.htm>. Acesso em: 15 jun. 2017.

VERAS, Érica Verícia Canuto de Oliveira. As hipóteses de prisão preventiva da lei Maria da Penha na visão do Superior Tribunal de Justiça. Revista Jurídica do Ministério Público do Estado de Minas Gerais, Belo Horizonte, v. 12, n. 21 jul/dez, 2013. Disponível em: <http://bdjur.stj.jus.br/jspui/handle/2011/69229?mode=full>. Acesso em: 27 nov. 2016.

Recebido em: 15/12/2016 Aceito em: 11/07/2017 
